\title{
A STUDY ON MORAL REASONING AND ACADEMIC ACHIEVEMENT OF SECONDARY SCHOOL STUDENTS IN SATHYAMANGALAM TALUK OF ERODE DISTRICT
}

\author{
Father Sri Marshal Joseph ${ }^{\mathrm{a}}$, and Dr. Jasmine Sudhanthira Devi ${ }^{\text {, }}$ \\ ${ }^{a}$ Ph.D. (Part-Time) Research Scholar School of Education PRIST University Vallam (Post) Thanjavur. Pin Code - 613403 \\ ${ }^{b}$ Professor \& Dean / Research Supervisor School of Education PRIST University Vallam (Post) Thanjavur. Pin Code - 613 \\ 403
}

Article History: Received: 11 January 2021; Accepted: 27 February 2021; Published online: 5 April 2021

\begin{abstract}
Moral reasoning is mainly focusing on making right decisions to do right activities and exhibit good behaviour of school students in a particular situation and it provides chances for them to discover and realize values, to build character and to improve personality. The findings reveal that there exits significant difference amongst moral reasoning of secondary school students and their profile. Moral reasoning is positively and moderately related with academic achievement of secondary school students. Hence, secondary school teachers should give proper guidance to their secondary school students for improving their moral reasoning and ethical and moral behaviours. Parents must provide conducive home environment for their secondary school students to enhance their abilities for moral reasoning and academic achievement. Furthermore, secondary school teachers should interact, discuss and exchange ideas regularly with their secondary school students for increasing their moral reasoning and academic achievement. Peer groups and family members must also give moral support to their secondary school students for improving their moral reasoning and academic achievement. In addition, secondary schools should conduct various programmes for enhancing moral reasoning and academic achievement among their secondary school students.
\end{abstract}

Key Words: Academic Achievement, Moral Reasoning, Secondary School Students

\section{Introduction}

One of the most important goals of school education is to generate an educated society that leads to intellectual and economic development of nation. Moral reasoning is an integral component teaching and learning process in school education (Tokic and Nikolic, 2017). Moral reasoning is a combination of ideas and thoughts which can be observed and assessed by school students by means of interactions and discussions with teachers and parents and friends (You Di and Penny, 2011). School teachers are involving in teaching and incorporating values among their students and also make them to think in terms of context and analytical ways (O'Flaherty and Gleeson, 2017). Moral reasoning is mainly focusing on making right decisions to do right activities and exhibit good behaviour of school students in a particular situation and it provides chances for them to discover and realize values, to build character and to improve personality (Kalsoom et al 2012). Further, moral reasoning is playing an important role in improving moral and ethical values and academic achievement of school students (Zhang, 2013). Nowadays, higher number of secondary schools in Tamil Nadu is realizing importance of moral education especially for secondary school students for enhancing their innovativeness, academic achievement and behaviour. Thus, it is essential to study moral reasoning and academic achievement of secondary school students.

\section{REVIEW OF RELATED LITERATURE}

Bouhmama (2020) found that moral reasoning among female graduate students was in low level and there existed no significant difference amongst different disciplines and moral reasoning. There existed significant difference amongst moral reasoning and locality of female graduate students.

Rafinda et al (2019) concluded that no significant difference exited among moral reasoning and students studying business ethics course between pre and post tests and this course failed in improving moral values and reasoning among them.

Githaiga et al (2018) revealed that moral reasoning was in moderate level for students. Significant difference exited amongst moral reasoning and gender of students and curriculum increased moral reasoning among students.

Levasseur et al (2017) indicated that moral reasoning was in high degree amongst high school students and there exited significant difference amongst moral reasoning and locality and gender of high school students.

Corcoran and O'Flaherty (2016) showed that college students had moral reasoning in medium level and their academic achievement had positive and significant relation with their moral reasoning. There exited significant difference among departments and male and female categories of college students with respect to their moral reasoning. 
Nichols (2015) mentioned that students studying in university were having high degree of moral reasoning and there exited significant difference among male and female students and their moral reasoning and it significantly influenced their academic achievement.

\section{SIGNIFICANCE OF THE STUDY}

Moral reasoning is having significant role in good conduct of secondary school students in school and home atmospheres and it is largely essential for them to understand which is good or bad activities and it is also highly related with their academic achievement. This study is highly useful to know the existing degree of moral reasoning of secondary school students and to what extent it is related with their academic achievement. The outcomes of this study are helpful to educationist and policy makers to include considerable changes in moral education for secondary school students and improving their academic achievement. This study is also useful to secondary school teachers and parents to adopt various strategies in order to improve moral reasoning and academic achievement of secondary school students.

\section{STATEMENT OF THE PROBLEM}

Secondary school students are involving in various academic and non academic activities and they are also engaging in different immoral practices. Since they are very young, they are failed to recognize and follow which is right or wrong in their activities and behaviour in their school and family environments and it is one of the important issues among secondary school students. It is the responsibility of secondary school teachers to teach ethical and moral values to their secondary school students and making them to follow those values in their learning and persona life. Parents and family environment are also playing a significant role in creating and managing better moral reasoning of their children. Moral reasoning is extremely crucial for them to select right path for their learning and personal life and to realize significance of values of school and home system in which they live around them. Moral reasoning of secondary school students is largely influenced by personal, internal and external environmental, social, cultural, ethical and moral factors. Further, moral reasoning is highly related with behaviour and academic achievement of secondary school students. Therefore, moral education is highly essential for secondary school students in order to enhance their moral reasoning and academic achievements in the current situation.

\section{TITLE OF THE STUDY}

A Study on Moral Reasoning and Academic Achievement of Secondary School Students in Sathyamangalam Taluk of Erode District

\section{OBJECTIVES OF THE STUDY}

i) To study the difference between moral reasoning of secondary school students regarding gender.

ii) To study the difference among moral reasoning of secondary school students regarding type of school

iii) To study the difference between moral reasoning of secondary school students regarding medium of instruction.

iv) To study the difference among moral reasoning of secondary school students regarding nature of schools.

v) To study the difference between moral reasoning of secondary school students regarding locality of schools.

vi) To study the relation between moral reasoning and academic achievement of secondary school students.

\section{OPERATIONAL DEFINITIONS OF MORALITY, MORAL AND VALUE}

Morality is the set of principles that guide what is good or bad activity. Moral is the codes that cover wrong or right behaviour of individuals. Value is how much something is worth. Moral reasoning stands for the way one uses the thought process in differentiating good from bad.

\section{HYPOTHESES OF THE STUDY}

i) There is no significant difference between moral reasoning of secondary school students regarding gender.

ii) There is no significant difference among moral reasoning of secondary school students regarding type of school

iii) There is no significant difference between moral reasoning of secondary school students regarding medium of instruction.

iv) There is no significant difference among moral reasoning of secondary school students regarding nature of schools.

v) There is no significant difference between moral reasoning of secondary school students regarding locality of schools.

vi) There is no significant relation between moral reasoning and academic achievement of secondary school students.

\section{METHODOLOGY}

Method of Study

This study is carried out in Sathyamangalam taluk of Erode district Survey method is applied for this study.

Tools Used in the Study

Self made questionnaire is used for this study. 


\section{Sampling Method}

Random sampling method is employed for the present study. 90 secondary school students are randomly selected in Sathyamangalam taluk of Erode district

Table-1. Profile of Secondary School Students

\begin{tabular}{|l|l|l|}
\hline Profile & Number (90) & Percentage \\
\hline Gender & 48 & \\
\hline Male & 42 & 53.33 \\
\hline Female & & 46.67 \\
\hline Type of School & 31 & \\
\hline Boys & 21 & 34.45 \\
\hline Girls & 38 & 23.33 \\
\hline Co-Education & & 42.22 \\
\hline Medium of Instruction & 47 & \\
\hline Tamil & 43 & 52.22 \\
\hline English & & 47.78 \\
\hline Nature of School & 33 & \\
\hline Government & 18 & 36.67 \\
\hline Government Aided & 39 & 20.00 \\
\hline Private & & 43.33 \\
\hline Locality of School & 65 & \\
\hline Urban & 25 & 72.22 \\
\hline Rural & 27.78 \\
\hline
\end{tabular}

Statistical Techniques Used

Profile of secondary school students is studied through percentages. Mean, standard deviation, t-test and ANOVA test are used to examine significant difference among moral reasoning and profile of secondary school students. Correlation analysis is applied to study relation between moral reasoning and academic achievement of secondary school students.

\section{INTERPRETATION OF DATA}

The profile of secondary school students is given in Table-1. The findings show that 53.33 per cent of them are male, while, 46.67 per cent of them are female and 42.22 per cent of them are studying in co-education schools, 34.45 per cent of them are studying in boys schools and 23.33 per cent of them are studying in girls schools. The findings indicate that 52.22 per cent of them are studying in Tamil medium, while, 47.78 per cent of them are studying in English medium and 43.33 per cent of them are studying in private schools, 36.67 per cent of them are studying in Government schools and 20.00 per cent of them are studying in Government aided schools and 72.22 per cent of them are studying in schools located in urban area, while, 27.78 per cent of them are studying in schools located in rural area,

Testing Hypothesis 1:

There is no significant difference between moral reasoning of secondary school students regarding gender.

Table-2. Difference between Moral Reasoning of Secondary School Students Regarding Gender

\begin{tabular}{|l|l|l|l|l|l|}
\hline Gender & $\mathbf{N}$ & Mean & $\begin{array}{l}\text { Standard } \\
\text { Deviation }\end{array}$ & t-Value & Sig. \\
\hline Male & 48 & 142.60 & 8.26 & $4.488^{* *}$ & $\mathrm{~S}$ \\
\hline Female & 42 & 149.75 & 6.86 & 26 \\
\hline
\end{tabular}

** Significant in $1 \%$ level

Mean value of moral reasoning for male and female category of secondary school students are 142.60 and 149.75 in sequence and it elucidates that female secondary school students are better in moral reasoning as compared to male secondary school students.

The t-value is 4.488 demonstrating that significant difference exits between gender of secondary school students and moral reasoning. So, null hypothesis is rejected.

Testing Hypothesis 2:

There is no significant difference among moral reasoning of secondary school students regarding type of schools.

Table-3. Difference among Moral Reasoning of Secondary School Students Regarding Type of Schools

\begin{tabular}{|l|l|l|l|l|l|}
\hline Type of School & N & Mean & $\begin{array}{l}\text { Standard } \\
\text { Deviation }\end{array}$ & F-Value & Sig. \\
\hline Boys & 31 & 143.71 & 8.79 & \multirow{2}{*}{$7.356^{* *}$} & \multirow{2}{*}{$\mathrm{S}$} \\
\hline Girls & 21 & 146.45 & 7.96 & & \\
\hline Co-Education & 38 & 149.95 & 6.48 & \\
\hline
\end{tabular}




\section{** Significant in $1 \%$ level}

Mean value of moral reasoning for secondary school students studying in boys, girls and co-education schools are $143.71,146.45$ and 149.95 in sequence and it elucidates that secondary school students studying in coeducation schools are better in moral reasoning as compared to secondary school students studying in boys and girls schools.

The F-value is 7.356 demonstrating that significant difference exits among type of school of secondary school students and moral reasoning. So, null hypothesis is rejected.

Testing Hypothesis 3:

There is no significant difference between moral reasoning of secondary school students regarding medium of instruction.

Table-4. Difference among Moral Reasoning of Secondary School Students Regarding Medium of Instruction

\begin{tabular}{|l|l|l|l|l|l|}
\hline $\begin{array}{l}\text { Medium of } \\
\text { Instruction }\end{array}$ & $\mathbf{N}$ & Mean & $\begin{array}{l}\text { Standard } \\
\text { Deviation }\end{array}$ & t-Value & Sig. \\
\hline Tamil & 47 & 145.77 & 9.20 & \multirow{2}{*}{$3.762^{* *}$} & $\mathrm{~S}$ \\
\hline English & 43 & 149.12 & 7.28 & \\
\hline
\end{tabular}

** Significant in $1 \%$ level

Mean value of moral reasoning for secondary school students studying in Tamil and English mediums are 145.77 and 149.12 in sequence and it elucidates that secondary school students studying in English mediums are better in moral reasoning as compared to secondary school students studying in Tamil Medium.

The t-value is 3.762 demonstrating that significant difference exits between medium of instruction of secondary school students and moral reasoning. So, null hypothesis is rejected.

Testing Hypothesis 4:

There is no significant difference among moral reasoning of secondary school students regarding nature of schools.

Table-5. Difference among Moral Reasoning of Secondary School Students Regarding Nature of Schools

\begin{tabular}{|l|l|l|l|l|l|}
\hline Nature of School & N & Mean & $\begin{array}{l}\text { Standard } \\
\text { Deviation }\end{array}$ & F-Value & Sig. \\
\hline Government & 33 & 144.64 & 9.23 & \multirow{2}{*}{$8.192^{* *}$} & $\mathrm{~S}$ \\
\hline Government Aided & 18 & 147.50 & 8.57 & & \\
\hline Private & 39 & 150.41 & 7,19 & \\
\hline
\end{tabular}

** Significant in $1 \%$ level

Mean value of moral reasoning for secondary school students studying in Government, Government aided and private schools are 144.64, 147.50 and 150.41 in sequence and it elucidates that secondary school students studying in private schools are better in moral reasoning as compared to secondary school students studying in Government and Government aided schools.

The F-value is 8.192 demonstrating that significant difference exits among nature of school of secondary school students and moral reasoning. So, null hypothesis is rejected.

Testing Hypothesis 5:

There is no significant difference between moral reasoning of secondary school students regarding locality of school.

Table-6. Difference among Moral Reasoning of Secondary School Students Regarding Locality of School

\begin{tabular}{|l|l|l|l|l|l|}
\hline Locality of School & $\mathbf{N}$ & Mean & $\begin{array}{l}\text { Standard } \\
\text { Deviation }\end{array}$ & t-Value & Sig. \\
\hline Urban & 65 & 147.95 & 7.46 & \multirow{2}{*}{$2.959^{* *}$} & $\mathrm{~S}$ \\
\hline Rural & 25 & 142.40 & 9.21 & \\
\hline
\end{tabular}

** Significant in $1 \%$ level

Mean value of moral reasoning for secondary school students studying in schools located in urban and rural area are 147.95 and 142.40 in sequence and it elucidates that secondary school students studying in schools located in urban are better in moral reasoning as compared to secondary school students studying in schools located in rural area.

The t-value is 2.959 demonstrating that significant difference exits between locality of school of secondary school students and moral reasoning. So, null hypothesis is rejected.

Testing Hypothesis 6:

There is no significant relation between moral reasoning and academic achievement of secondary school students.

Table-7. Relation between Moral Reasoning and Academic Achievement of Secondary School Students

\begin{tabular}{|l|l|l|}
\hline Particulars & Correlation Coefficient & Sig. \\
\hline Relation between Moral Reasoning and & $0.54^{* *}$ & S \\
\hline
\end{tabular}




\author{
Academic Achievement of Secondary \\ ** Significant in $1 \%$ level \\ The correlation coefficient between moral reasoning and academic achievement of secondary school students is \\ 0.54 and it explains that they are positively and moderately inter related. So, null hypothesis is rejected.
}

\title{
FINDINGS
}

1) Significant difference exits between moral reasoning of secondary school students regarding gender. Female secondary school students are better in moral reasoning as compared to male secondary school students.

2) Significant difference exits among moral reasoning of secondary school students regarding type of schools. Secondary school students studying in co-education schools are better in moral reasoning as compared to secondary school students studying in boys and girls schools.

3) Significant difference exits between moral reasoning of secondary school students regarding medium of instruction. Secondary school students studying in English mediums are better in moral reasoning as compared to secondary school students studying in Tamil Medium.

4) Significant difference exits among moral reasoning of secondary school students regarding nature of schools. Secondary school students studying in private schools are better in moral reasoning as compared to secondary school students studying in Government and Government aided schools.

5) Significant difference exits between moral reasoning of secondary school students regarding locality of school. Secondary school students studying in schools located in urban are better in moral reasoning as compared to secondary school students studying in schools located in rural area.

6) Significant relation exits between moral reasoning and academic achievement of secondary school students. Moral reasoning and academic achievement of secondary school students are positively and moderately inter related.

\section{CONCLUSION}

The foregoing analysis reveals that there exits significant difference amongst moral reasoning of secondary school students and their profile. Moral reasoning is positively and moderately related with academic achievement of secondary school students. Hence, secondary school teachers should give proper guidance to their secondary school students for improving their moral reasoning and ethical and moral behaviours. Parents must provide conducive home environment for their secondary school students to enhance their abilities for moral reasoning and academic achievement. Furthermore, secondary school teachers should interact, discuss and exchange ideas regularly with their secondary school students for increasing their moral reasoning and academic achievement. Peer groups and family members must also give moral support to their secondary school students for improving their moral reasoning and academic achievement. In addition, secondary schools should conduct various programmes for enhancing moral reasoning and academic achievement among their secondary school students.

\section{REFERENCES}

1. Andrea Tokic, \& Matilda Nikolic. (2017). Moral reasoning among croatian students of different academic orientations. Paper Presented on $13^{\text {th }}$ International Conference on Social Sciences, Vienna.

2. Ascaryan Rafinda,Tímea Gal, \& Putri Purwaningtyas. (2019). Business ethics course on student moral reasoning. Oradea Journal of Business and Economics, 4(1), $\quad 60-68$.

3. Ouada Jamoussi, H. B., \& Makhlouf, E. M. (2018). School Performance and the Education Systems' Efficiency: An International Comparison Based on OECD PISA Surveys. International Journal of Human Resources Management (IJHRM) ISSN (P), 2319-4936.

4. Caroline Levasseur, Nadia Desbiens, \& François Bowen. (2017). Moral reasoning about school bullying in involved adolescents. Journal of Moral Education, 46(2), 158-176.

5. Djilali Bouhmama. (2020). Assessment of principled moral reasoning of a female sample of graduate students in education. Paper Presented in 2nd International Conference on Advanced Research in Educateion, Teaching \& Learning, Berlin, Germany.

6. Jon Nichols. (2015). Moral reasoning among Taiwanese liberal arts students: conventional morality is not enough. Education Journal, 4(5), 207-213.

7. DHAYALAN, V., SENTHILNATHAN, C., VENKATESH, P., \& KRISHNAMOORTHY, M. SAVING HABIT AND INVESTMENT PREFERENCE OF GOVERNMENT SCHOOL TEACHERS IN VELLORE DISTRICT.

8. Kalsoom, F., Behlol, M.G, Kayani, M.M., \& Kaini, A. (2012). The moral reasoning of adolescent boys and girls in the light of gilligan's theory international education studies. International Education Studies. 5(3), 15-23. 
9. O'Flaherty, J., \& Gleeson, J. (2017) Irish student teachers' levels of moral reasoning: context, comparisons, and contributing influences. Teachers and Teaching, 23(1), 59-77.

10. Wang, T. C., \& Hsieh, H. C. (2017). An analysis of school-based curriculum development; The Taiwanese School of Melbourne. Internafional Journal of Business and General Management, 6(1), 17-24.

11. Pauline Wanjiru Githaiga, Joseph Mworai Wamutitu, \& Lydia Nkatha Kinuthia. (2018). Enhancement of secondary schools students' moral reasoning through the Christian religious education curriculum in Nakuru county, Kenya. Journal of Education and Practice, 9(26), 90-98.

12. ELUMALAI, G., CHANDRAMOHAN, D., \& SANKARAVEL, M. THE OBESITY LEVEL AND ABDOMINAL FAT AMONG A RURAL TAMIL SCHOOL STUDENTS IN MALAYSIA.

13. Roisin P Corcoran, \& Joanne O'Flaherty. (2016). Examining the impact of prior academic achievement on moral reasoning development among college students: A growth curve analysis. Journal of Moral Education, 45(4), 1-16.

14. EZE, K. O., UGWUANYI, C. S., \& OKEKE, C. I. (2020). Extent of the Upper Basic Education French Language Curriculum Content-Delivery with Technologies in Nigerian Secondary Schools. International Journal of Mechanical and Production Engineering Research and Development(IJMPERD), 10(4), 311-318.

15. You Di., \& Penny, N. H. (2011). Assessing students' moral reasoning of value based. Psychology Research, 1(6), 385-39.

16. Zhang, X. (2013). Children's moral reasoning: Influence of culture and collaborative discussion. Unpublished Masters Thesis. University of Illinois, Urbana-Champaign.

17. Silva, A. F., \& Fiamenghi-Jr, G. A. (2018). School inclusion of autistic children: Case study in a Brazilian kindergarten school. International Journal of Humanities, Arts, Medicine and Sciences (BEST: IJHAMS), 6(11), 7-12. 